\title{
Experimental Study on Fractional Substitute of Cement with Glass Powder and Egg Shell Powder
}

\author{
K. Srinivasan, A. Manikandan, S. Manjupriya
}

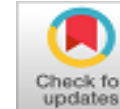

\begin{abstract}
Glass waste \& Egg Shell Powder cannot be processed for useful applications and may end up in a landfill. In India nearly 30 tonnes of Glass waste in every metropolitan city generated every year. This establishes the ecological problem and is measured an additional problem on the previouslyclose-fitting landfill space.This article studies the possibility of using postconsumer Glass Waste Powder and Egg Shell in Powder form as a fractional substitute for conservative cement on concrete. During manufacturing of cement it emits a huge carbon di oxide and cause various effect to atmosphere. In this project tried to minimize the usage of cement by partial replacement of waste material from general utilities. Here I replaced cement by partial as glass powder and egg shell powder with a percentage of $0 \%$, $20 \%, 30 \%$, and $40 \%$ and for its compressive strength up to 7,14 and 28 Ages evaluate the strength properties. Comparison result has obtained by cube test \& split tensile test. Since now a day's the developing and developed countries are facing lack of post consumer dumping site and it has become extremely serious difficulty. This waste product should convert resource of byproduct to control environmental pollutions.
\end{abstract}

Key words: Egg shell fine particles, Waste Glass powder, salvage, compressive strength, tensile strength.

\section{INTRODUCTION}

$\mathrm{A}_{\mathrm{n}}$ awareness of the edifice culture by means of waste or used materials in concrete is rising since the importance positioned on sustainable construction "ArashBarazesh et al. (2005)", the waste glass from in and around the small shops is packed as a waste and disposed as landfill "Freire and Holanda (2006)" . Glass is an inert material which could be recycled and used a lot of times without varying its chemical belongings .As sound using waste glass as cullet in glass industrialized, waste glass is flattened into meticulous sizes for employ as aggregate in a mixture of applications such as water filtration, grind plastering, "Idir R., Cyr M., and Tagnit-Hamou A. (2009)" sand envelop for activity territory and sand substitute in concrete. Since the order in the concrete industrial is escalating day by day, the employ of river sand as fine aggregate guide to utilization of normal possessions, subordinate of water table, plummeting of the bridge piers, etc as a frequent treat Dale P. et al. (2009).

Manuscript received on January 03, 2020.

Revised Manuscript received on October 11, 2021.

Manuscript published on October 30, 2021.

* Correspondence Author

K.Srinivasan*, Assistant Professor, Dr. Mahalingam College of Engineering And Technology, Pollachi, (Tamil Nadu), India

A.Manikandan, Assistant professor, Dr. Mahalingam College of

S.Manjupriya, Associate Professor, Dr. Mahalingam College of Engineering And Technology, Pollachi, (Tamil Nadu), India

(C) The Authors. Published by Blue Eyes Intelligence Engineering and Sciences Publication (BEIESP). This is an open access article under the CC BY-NC-ND license (http://creativecommons.org/licenses/by-nc-nd/4.0/) Engineering And Technology, Pollachi, (Tamil Nadu), India

Challenge has been completed in by means of flattened goblet as fine collective and Egg Shell fine dust in the substitute of river sand.

- To augment the strength by substitute of waste resources.

- $\quad$ Diminish the fabric cost.

- $\quad$ To reduce the environmental pollution.

- $\quad$ Reprocess the waste material.

- $\quad$ Curtail the cement convention.

- $\quad$ Easy grounding.

- Waste resources effortlessly available with very stumpy cost.

A. Methodology of employment of Glass Powder \& EGG Shell

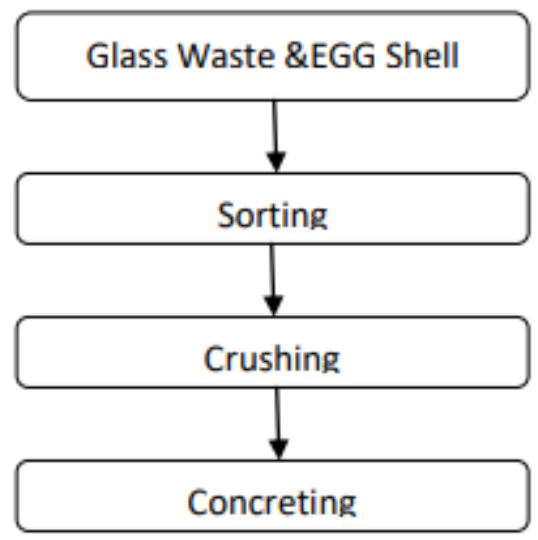

Fig.1.-Methodology

\section{EXPERIMENTAL PROGRAM}

The purpose of this plan is to recount the potency and additional property of normal traditional concrete with post consumer plastic aggregate barter concrete with special size of plastic and discover the most favorable satisfied of plastic which can be used as substitute in concrete for a safe and constant structure. The early exams were determined of detailed gravity of the fine aggregates and coarse aggregates and Waste plastic aggregates pursue with the water amalgamation test for plastic. Subsequently the concrete design mix was effort for M20 grade and the mix was place by volume batching since plastic has moderately reduced weight to aggregates. The additional percentage of plastic was calculated and workability tests like the slump cone and Vee Bee were done to find their easiness and flow ability. As results were good the work was pave the way with the compressive strength, gash tensile and flexural strength examination.

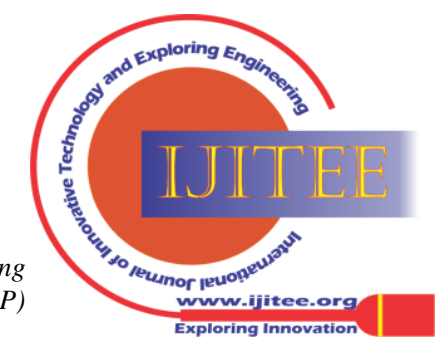




\section{Experimental Study on Fractional Substitute of Cement with Glass Powder and Egg Shell Powder}

The firmness and gash tensile strengths were finished for concrete with $0 \%, 5 \%, 10 \%, 15 \%, 20 \%$ and $25 \%$ of plastic replacement with the coarse aggregates.

Compression test was through with the cubes with dimension $150 \mathrm{~mm} * 150 \mathrm{~mm} * 150 \mathrm{~mm}$.

Three cubes were casted for each percent of replacement for 7, 14 and 28 days of testing. Totally 54 cubes were casted and tested to find their compressive strength and compare to standard concrete. Before testing their weight variation was also computed. Two cylinders of $150 \mathrm{~mm}$ diameter and $300 \mathrm{~mm}$ height were cast for each percent of replacement 7 , 14 and 28 days of testing with a total of 36 cylinders to check the gash tensile. The flexural potency be resolute via beams of dimension $500 \mathrm{~mm} * 100 \mathrm{~mm} * 100 \mathrm{~mm}$. Two beams were tested for each percentage at 7, 14 and 28 days. Totally 36 beams were tested to compare the flexural strength from conventional concrete.

\section{TEST RESULTS}

\subsection{Physical Properties of Egg Shell}

Table .1. Physical Properties of Egg Shell

\begin{tabular}{|l|l|l|}
\hline S.no & Physical properties & values \\
\hline 1. & Precise gravity & 0.84 \\
\hline 2. & Moisture contented & 1.21 \\
\hline 3. & Bulk density $(\mathrm{g} / \mathrm{m} 3)$ & 0.8 \\
\hline 4. & limited density $(\mathrm{g} / \mathrm{m} 3)$ & 1.012 \\
\hline 5. & porosity & $22.4 \mathrm{BET}$ \\
\hline 6. & Surface area $(\mathrm{m} 2 / \mathrm{g})$ & 21.2 \\
\hline
\end{tabular}

\subsection{Physical Properties of Glass Powder}

Table .2. Compound property of Waste Glass Powder

\begin{tabular}{|l|l|l|}
\hline s.no & Compound properties & value \\
\hline 1. & $\mathrm{pH}$ & 10.215 \\
\hline 2. & color & Grayish white \\
\hline
\end{tabular}

Table . 3. Corporal Properties of Waste Glass Powder

\begin{tabular}{|l|l|l|}
\hline s.no & Physical properties & values \\
\hline 1. & Precise gravity & 2.6 \\
\hline 2. & fine quality passing 150 & 99.5 \\
\hline 3. & Fineness passing 90 & 98 \\
\hline
\end{tabular}

\subsection{Combination of Materials}

20\% Replacement $=15 \%$ Glass Powder + 5\% EGG Shell Powder

$30 \%$ Replacement $=25 \%$ Glass Powder + 5\% EGG Shell Powder

40\% Replacement $=35 \%$ Glass Powder + 5\% EGG Shell Powder

\subsection{Workability Test Results}

Slump Cone Test

Slump Value $\quad=82 \mathrm{~mm}$

Vee Bee Consistometer

Vee Bee Time $=18 \mathrm{sec}$.

\subsection{Compressive potency Test}

The compressive potency of the concrete cubes for M20 grade is resolute from the testing machine. The results are shown in Table 4.

Table 4. Compressive potency of concrete

\begin{tabular}{|l|l|l|l|l|}
\hline s.no & \multirow{2}{*}{$\begin{array}{l}\text { \% of GP } \\
\text { \& ESP }\end{array}$} & \multicolumn{4}{|l|}{ Compressive strength (N/mm2) } \\
\cline { 3 - 5 } & & 7 days & 14 days & 28 days \\
\hline 1 & $0 \%$ & 15.5 & 18 & 23 \\
\hline 2 & $20 \%$ & 13.39 & 15.32 & 24 \\
\hline 3 & $30 \%$ & 14 & 16.38 & 24.67 \\
\hline 4 & $40 \%$ & 12.12 & 16 & 20 \\
\hline
\end{tabular}

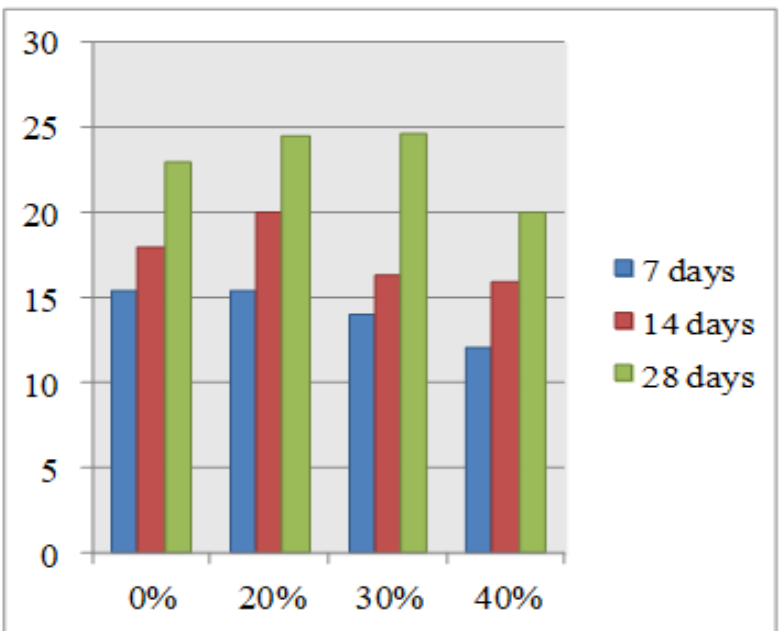

Chart 1. Compressive potency of concrete since the consequences is renowned that the compressive potency decreased with the augment in substitute of plastic. But the strength is acceptable up to20\% replacement. Above 25\% the cubes do not satisfy the required strength. Hence $20 \%$ replacement can be adopted based on the compressive strength result.

\subsection{Gash Tensile Test}

The gash tensile potency of the concrete cylinder of $\mathbf{M}_{20}$ was resolute from the compression testing apparatus.

The results are shown in Table 3.2.

Table 5. Split Tensile Strength of concrete

\begin{tabular}{|c|c|c|c|c|}
\hline \multirow{2}{*}{ S.no } & \multirow{2}{*}{$\begin{array}{c}\text { \% of GP } \\
\text { \& ESP }\end{array}$} & \multicolumn{3}{|c|}{ Split tensile strength } \\
\cline { 3 - 5 } & & 7 days & 14 days & 28 days \\
\hline 1 & $0 \%$ & 3 & 4.5 & 8 \\
\hline 2 & $20 \%$ & 2.5 & 3 & 7.8 \\
\hline 3 & $30 \%$ & 2.75 & 4 & 7.75 \\
\hline 4 & $40 \%$ & 1.8 & 2.98 & 6.13 \\
\hline
\end{tabular}

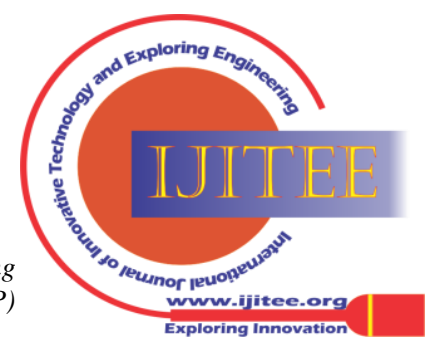




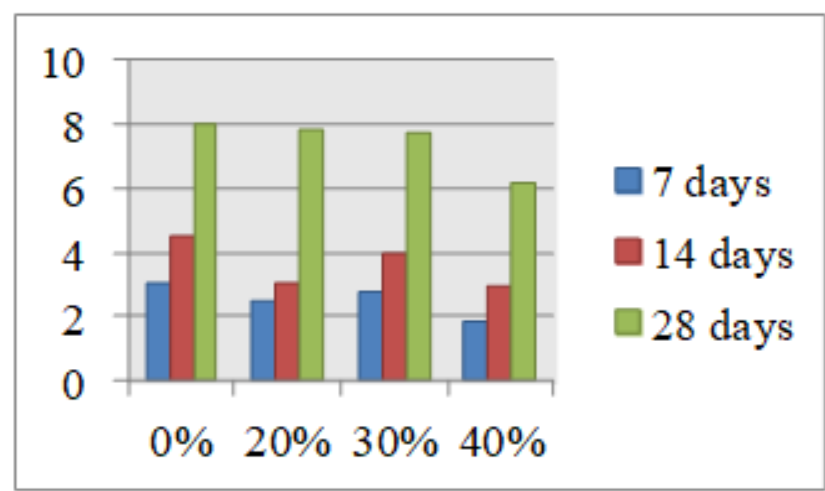

Chart 2. Split Tensile Strength of concrete. The Split tensile strength of normal concrete is $10 \%$ of its compressive strength. From the results the split tensile strength also decreased with increase in replacement of plastic. Upto 20\% replacement the split tensile strength is also acceptable. Above $20 \%$ the replacement is not safe based on split tensile strength also.

\section{FUTURE OF PCPW AS CONCRETE INGREDIENT}

The idea to use Glass \& Egg Shell powder waste as concrete constituent will product in its large volume disposal which is ecologically safe and does not posture any health hazard. At current these trials are typically limited to laboratory or research level. However, these inquiriesposture a big challenges to provide a bridge to gap the laboratory works and real applications. The procedure of making GP \& ESP suitable for concrete is energy concentratedbut if an energy efficient method is developed then this work will be of high energy performance, low cost and eco-friendly. A significant experimentation is required for its formulation. Durability aspects of concrete using different types of PA aggregate require thorough investigation. An in-depth experimental analysis of mechanical behaviour of concrete containing PA aggregate needs an urgent attention which will be of great advantage to the world.

\section{CONCLUSION}

Subsequentassumptions can be drawn from the practice of GP \& ESP as partial substitution of cement in concrete, The result variation of compressive strength and split tensile potency of concrete formed cement with GLASS powder and EGG fine shell powder for 7, 14 \& 28 days. From above said combinations $30 \%$ ( $25 \%$ of GLASS powder $+5 \%$ of EGG fine shell powder) achieved good workability. Compressive potency and gash tensile potency of concrete then the other combinations. So it shows the optimum and recommended for the structural purpose.

\section{REFERENCES}

1. O. Amu. A.B.Fajobi., B.O. Oke., (2005). "Effect of eggshell powder on the stabilize possible of lime on an expansive clay soil", Res. J. Agric.\& Biol. Sci, 1: 80 - 84.DOI: 10.3923/jas.2005.1474.1478.

2. Adaway, M \& Wang, Y 2015, 'Recycled glass as a partial replacement for fine aggregate in structural concrete-Effects on compressive strength', Special Issue: Electronic Journal of Structural Engineering, vol. 141, pp. 116-122.

3. ArashBarazesh., Hamidrezasab., MehdiGharib., and MoustafaYousefiRad, (2012). "Laboratory Investigation of the Efffect of Eggshell powder on Plasticity Index in Clay and Expansice soils", European Journal of Experimentl Biology, pp 2378-2384.

4. ASTM Annual Book of Standards (2004). Cement; Lime; Gypsum, West Conshohocken PA, Vol.04.01.

5. J.J.Beaudoin., and R. F.Feldman., (1979). "Partial replacement of cement by fly ash in autoclaved products theory and practice", International Journal of material science Vol. 14, pp. 1681-1693, https://doi.org/10.1007/BF00569291.

6. K.Chinnaraju.., K.Subramanian, and S.R.R Senthilkumar., (2010). "Strength properties of HPC using binary, ternary and quaternary cementitious blends structural concrete", Thomas Telford, pp. 14644177.

7. P.Dale., Bentz, F.Edgardo., Irassar., Brooks Bucher and W. Jason Weiss. (2009). "Limestone Fillers to Conserve Cement in Low w/cm Concretes: An Analysis Based on Powers”, Concrete International, 31 (11) and (12): 41-46 and 35-39, DOI: 10.12691/ajcea-4-4-4.

8. M.N.Freire., and J. N. F.Holanda., (2006). "Characterization of avian eggshell waste aiming its use in a ceramic wall tile paste", Journal of Ceramica, Vol. 52, pp. 240-244, http://dx.doi.org/10.1590/S036669132006000400004.

9. R.Idir., M .Cyr., and A.Tagnit-Hamou (2009). "Use of Waste Glass as Powder and Aggregate in Cement-Based Materials" SBEIDCO - 1st International Conference on Sustainable Built Environment Infrastructures in Developing Countries ENSET Oran (Algeria) 50, DOI: 10.1016/j.conbuildmat.2009.12.030.

10. Lau Yih Bing,(2010). Effect of Foamed Concrete with Albumen Concrete, University of Malaysia, Pahang, Institution open access Journal.vol 33, pp 339-342,DOI: 10.13140/RG.2.1.3643.1767.

\section{AUTHOR PROFILE}

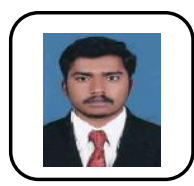

K. Srinivasan is working as an assistant professor in the department of Civil Engineering, Dr. Mahalingam College of engineering and technology, Pollachi, Tamil Nadu, India. His research interests include construction materials, concrete technology, and environmental engineering.

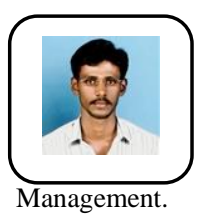

A.Manikandan is working as an assistant professor in the department of Civil Engineering, Dr. Mahalingam College of engineering and technology, Pollachi, Tamil Nadu, India. His research interests include construction materials, concrete technology, and construction

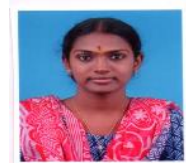

S.Manjupriya is working as an associate professor in the department of Civil Engineering, Dr. Mahalingam College of engineering and technology, Pollachi, Tamil Nadu, India. His research interests include contaminant transport modeling.

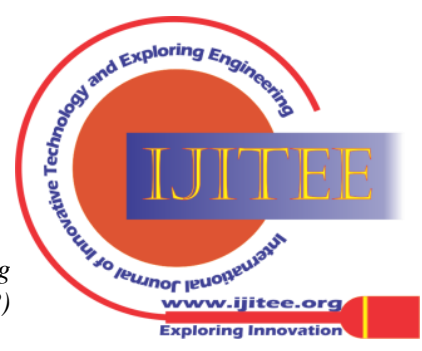

